Cuadernos de Filología Clásica. Estudios Latinos

ISSN: 1131-9062

https://dx.doi.org/10.5209/cfcl.67104

EDICIONES

COMPLUTENSE

\title{
J. A. Estévez Sola, Historia Silensis - Chronica Hispana saeculi XII. Pars III (Corpus Christianorum. Continuatio Mediaeualis, 71B), Turnhout, Brepols, 2018, 265 pp.
}

En el año 2018, y de la mano de Juan Antonio Estévez Sola, vio la luz en el Corpus Christianorum la edición crítica de una de las crónicas más importantes del medievo hispánico: la llamada Historia Silensis -así denominada por la tradicional hipótesis, hoy abandonada, de su origen en Silos-, a veces conocida como Historia Legionensis, por su redacción en realidad en ambiente leonés. En ella su autor se propuso, al menos en principio, relatar la vida y obra del rey Alfonso VI (1040/41-1109); sin embargo, el texto transmitido no lleva a término este propósito, ya sea porque el relato quedó sin concluir (por la muerte de su autor $\mathrm{u}$ otra circunstancia), ya sea porque la parte final de la obra se ha perdido (por mutilación temprana), o ya porque su autor cambiara de objetivo a lo largo de la redacción ( $c f$. pp. 69-73 esp. 72-73, con un análisis muy interesante de esta última posibilidad).

Por la importancia de la obra -que es fuente de Lucas de Tuy y de la Chronica Naierensis, es testimonio indirecto de la Crónica de Sampiro y está escrita en un cuidado estilo imitador de Salustio-, la presente edición era una publicación largamente esperada en los estudios de filología e historia medieval. En la Introducción, de algo más de un centenar de páginas (pp. 7-120), Estévez Sola aborda con gran claridad los numerosos puntos problemáticos que presenta esta obra, que Francisco Rico definió como todo un «semillero de problemas» (cf. p. 69 n. 55). La primera parte de la Introducción (pp. 7-54) está consagrada a sus diez testimonios manuscritos hoy conocidos (curiosamente, todos conservados en la Biblioteca Nacional, en Madrid), que por primera vez son estudiados en su integridad. En lugar de la tradicional división de este análisis en dos epígrafes (una descripción de los códices, por un lado, y un estudio de sus relaciones estemáticas, por otro), Estévez Sola aborda su clasificación a medida que se van presentando los manuscritos. El principal manuscrito que nos ha transmitido la obra -en torno al cual orbita el resto de la tradición y en el que desemboca una única rama desde el arquetipo, cf. stem$m a-$, es el códice $B=$ Madrid, Biblioteca Nacional de España, 1181, de medidos del s. XV. El estudio de Estévez Sola es particularmente detallado al abordar las divergencias entre este manuscrito y su copia más antigua, el códice 8592 de la misma sede, que recibe la sigla $C$ y que Manuel Gómez Moreno o Justo Pérez de Úrbel consideraron un autógrafo del inquisidor dominicano Felipe de Barbieri -en una publicación en preparación mostraremos que el códice no es, en realidad, de la pluma de este religioso siracusano-. En efecto, este segundo manuscrito ofrece, en ciertos pasajes, algunas lecciones excelentes, pero en la mayoría de tales puntos la corrupción de $B$ es visible y la enmienda, factible: en otros términos, en un texto de esta extensión no consta en $B$ ningún auténtico error separativo que no esté también reiterado en $C$. Decía P. Maas que un solo caso seguro de error separativo basta y que cien dudosos no son suficientes; pues bien, en este punto, $B$ no ofrece 
ningún caso seguro, por lo que la conclusión más probable es que $C$ es un descendiente de $B$ y sus lecturas superiores, correcciones.

Estamos de acuerdo con esta conclusión. Un caso interesante en este sentido es el texto de 20, 590 (cf. pp. 30-31), donde $B$ lee un lumine insostenible y $C$, en cambio, lumine orbatum: es cierto que en este punto $C$ está libre de una falta de $B$, porque un participio es necesario, pero, a nuestro juicio, precisamente la falta en $B$ es tan evidente -lumine queda descolgado sintácticamente- que la corrupción es perfectamente identificable y, por tanto, es seguro que el escriba de $C$ tenía, por ponerlo en términos de G. Pasquali, el necesario «estímulo para conjeturar». Prueba de ello, añadimos, es que, de manera independiente, el escriba de otro códice, $Q$, añadió en el margen orbum, con el mismo sentido de orbatum, y que la adición de priuatum por parte de los editores anteriores del texto ha sido unánime. Que $C$, en este sentido, es un copista activo y que sus lecciones deben juzgarse con mucha prudencia en términos estemáticos es visible en otro pasaje como 41, 1687 (cf. p. 34), donde la ausencia de un verbo de dicción es segura (de nuevo es una falta evidente) y $C$ añade uocat (la Chronica Naierensis invita a restituir monet y señala uocat como conjetura de $C$ ); igualmente, en 43, 1794 ( $c f$. p. 34) en lugar del suorum generali conuentu de $B$ el códice $C$ lee suorum consilio in generali conuentu, pero el texto de $B$ está confirmado por la tradición indirecta. Pasajes como estos confirman que $C$ es un códice intervencionista, lo que permite aparentemente enmascarar su dependencia estemática de $B$. En las páginas que siguen (pp. 37-54) se pasa revista a las relaciones entre $B$ y el resto de testimonios de la tradición manuscrita, de los cuales tres derivan de la edición de F. Berganza (Madrid, 1721) y esta, a su vez, de un códice perdido de Fresdeval.

La segunda parte de la Introducción (pp. 55-69) examina las ediciones de la obra, comenzando por la del citado Berganza (reimpresa en Acta Sanctorum) y siguiendo por las de E. Flórez, F. Arévalo (solo de los capítulos 41-42), A. Huici (que es reproducción del texto de Flórez), F. Santos Coco y, finalmente, J. Pérez de Úrbel y A. González Ruiz-Zorrilla, la última publicada hasta el presente trabajo. La tercera parte (pp. 69-115) aborda los principales problemas de la obra: su construcción, la interpolación de la Crónica de Sampiro - que abarca desde Alfonso III a Alfonso V, esto es, la segunda mitad del s. X-, su autoría, fecha y lugar de redacción, sus fuentes, su tradición indirecta y su estilo. Desde Silos a Sahagún, desde León a Oviedo, el marco geográfico en que se gestó la obra ha sido sumamente discutido; y desde Alón el gramático a Pelayo de Oviedo, pasando por Ordoño Sisnándiz - canónigo en San Isidoro de León en la primera mitad del s. XII-, varios han sido los intentos de identificar al autor de este anónimo relato historiográfico. Estévez Sola pasa revista a todos ellos. La data propuesta alcanza el arco entre 1109 y 1133 ; su ubicación se sitúa en ambiente leonés y no castellano, sin que sea posible especificar con certeza una localización exacta. Es extremadamente original la defensa que hace el editor de la posible autenticidad de una oscura expresión, domus seminis, que ha hecho correr ríos de tinta y que usualmente se ha interpretado como un texto corrupto, corregido de diversos modos; Estévez Sola desarrolla una prudente argumentación sobre el hecho de que, si alude a un centro monástico en que profesó nuestro autor (quizás San Isidoro de León), tal monasterio no tiene por qué coincidir necesariamente con el lugar preciso en que se compuso la obra. Por su parte, el estudio de fuentes, tanto históricas como estilísticas - entre las que destacan Salustio, la Ilias Latina o Eginardo- es particularmente interesante no solo para la constitución del texto, sino para 
demostrar la unidad de la obra, que a menudo ha sido objeto de críticas en este sentido. Es también elocuente la demostración de que, a la hora de caracterizar un hecho o personaje determinado del relato, el uso de una fuente u otra (ej., pasajes de la Ilias Latina o del De coniuratione Catilinae referidos en su contexto original a un personaje, como Menelao o Catilina) no implica, en realidad, una clave interpretativa.

Por lo que se refiere a la tradición indirecta, a la influencia sobre el Chronicon mundi de Lucas de Tuy y sobre la Chronica Naierensis (editada por Estévez Sola en 1995, dentro de la misma colección), el editor añade la Historia translationis sancti Isidori y la Translatio sancti Emiliani. Algún pasaje nos parece particularmente interesante: en 21, 679 (omnem armorum et equorum multitudinem simul spolia ex diuersiis uictoriis congesta ... amisit) los códices de la Historia Silensis leen multitudinem; la Chronica Naierensis y Lucas de Tuy, fortitudinem. Dado que el influjo de la Historia Silensis sobre la Naierensis y Lucas de Tuy parece independiente (aunque en época del segundo ya se conocía la primera, $c f$. p. 101), en este punto se reducen las posibilidades básicas: si el texto original de la Historia Silensis fuese fortitudinem (que tal vez sería difficilior en el contexto), el multitudinem sería un error presente en el arquetipo ya corrupto de la tradición manuscrita; pero si el texto correcto es multitudinem, como edita Estévez Sola (p. 168), en tal caso los ejemplares que manejaron Lucas de Tuy y el autor de la Naierensis remontan en último término, por vía directa o indirecta, a un modelo común que ya contenía la corrupción, porque una sustitución semejante no puede producirse de manera independiente (la otra opción teórica pasaría por aceptar un influjo de la Chronica Naierensis en Lucas de Tuy, pero la independencia de ambos parece clara). El repaso del estilo, por último, complementa el estudio de la lengua debido a Á. Escobar, «La lengua de la Historia Silensis», e-Spania 14 (2012), url: <http://journals.openedition.org/e-spania/21644> [Consulta: 04/11/2019].

Cierra la introducción una sección dedicada a los criterios de edición (pp. 115120). De estos destacan en particular, también por su interés metodológico, los principios relativos al empleo de fuentes y tradición indirecta, en la idea de no reescribir los textos latinomedievales a partir de las fuentes, suponiendo que, ante la divergencia entre las fuentes y los códices (en particular tardíos o corruptos), debe preferirse de manera apresurada la lección de las fuentes, y no la de la tradición directa. El criterio de optar por el texto de la fuente, frente al de los manuscritos, cuando el primero cuenta con el apoyo de la tradición indirecta de la obra, nos parece un elemento de juicio excelente en este caso. Ni que decir tiene que en no pocos casos la divergencia entre el texto de la obra y el texto estándar de la fuente se debe a que el autor de la primera utilizó códices corruptos de sus fuentes, y la divergencia halla su explicación en los aparatos críticos de la fuente empleada, como ilustra Estévez Sola (pp. 117-118). En cualquier caso, los problemas descritos y las soluciones adoptadas revelan una reflexión muy reposada sobre cada uno de estos pasajes de selectio problemática entre tradición directa, fuentes y tradición indirecta.

Por último, contamos con una bibliografía dividida en Ediciones de la obra, Fuentes y Estudios (pp. 121-130), a la que hacemos una adición, aparecida de manera simultánea o posterior a la publicación de la edición y debida a uno de los mejores conocedores de la obra: Georges Martin, que vuelve a defender la autoría de Ordoño Sisnández: «Ordoño Sisnández, autor de la Historia legionensis. Versión revisada y aumentada», e-Spania 30 (2018), url <https://journals. openedition.org/e-spania/28195> [Consulta: 04/11/2019]; el propio Georges 
Martin ha vuelto a abordar el tema de la autoría en su reseña de esta edición, publicada también en e-Spania 32 (2019), url <http://journals.openedition.org/espania/30150> [Consulta: 04/11/2019].

Sigue a continuación el texto crítico de la edición (pp. 133-231). La ratio edendi seguida por Estévez Sola es coherente con las conclusiones estemáticas obtenidas, y con los criterios relativos al uso de fuentes y tradición indirecta. El códice $B$ sirve de base, pero la edición no es una transcripción paleográfica de $B$ : el texto de este códice, en torno al que gira la tradición de la obra, está en no pocos puntos corrupto y el editor en ellos opta por la lectura de alguno de los restantes testimonios. El texto latino es claro, limpio y bien puntuado. Se ha introducido una nueva división y numeración de capítulos, plenamente justificada en este caso por la numeración inexistente o absurda de ediciones anteriores ( $c f$. p. 119). Bajo el texto constan cuatro aparatos ( $c f$. , por ejemplo, p. 140). Como es norma en las ediciones de Brepols, se distinguen las fuentes literarias de las bíblicas, que ocupan un primer aparato exento. Un acierto de la edición de Estévez Sola es, en cambio, que las informaciones que en ocasiones se aúnan en un único aparato de fuentes literarias, loci paralleli, imitadores, tradición indirecta, etc., aparecen separadas en dos aparatos diferentes, impresos bajo el dedicado a las referencias bíblicas. En el primero constan las referencias a textos precedentes, esto es, fuentes, modelos literarios, estilísticos o históricos, paralleli antiguos o altomedievales, etc.; el siguiente aparato, el tercero de los cuatro, está dedicado en exclusiva a los loci excerpti, esto es, a la tradición indirecta, fundamentalmente la Chronica Naierensis y el Chronicon mundi de Lucas de Tuy y, en menor medida, las citadas Translationes. Este establecimiento de dos aparatos diversos nos parece uno de los grandes aciertos de esta edición. Es cierto que en algunos casos es de difícil aplicación, en particular, en el caso de paralelos problemáticos en los que no es posible establecer con seguridad la relación de dependencia y clarificar qué texto ha dado lugar a cuál, o si ambos derivan de una fuente intermedia común -este es el problema que afecta al Chronicon Compostellanum, cf. pp. 105-106-; en el grueso de casos, en cambio, es una manera muy clara de distinguir dos órdenes de información en sí mismos diferentes y, sobre todo, enormemente importantes en la constitutio textus de las obras latinomedievales.

Bajo el aparato de loci excerpti consta el aparato crítico sensu stricto, que refleja las variantes textuales de todos los códices conocidos (no las ortográficas, que son inútiles en una tradición como la presente), las propuestas de editores y eruditos precedentes, y las intervenciones del propio Estévez Sola. Igualmente, en determinados casos particularmente interesantes y de selectio más dudosa, el editor recoge con precisión, citando la referencia exacta de cada pasaje, las lecturas de las fuentes, loci paralleli y tradición indirecta más sugestivas y relevantes; este proceder es más exigente para el editor, pero es mucho más exacto que otras indicaciones más imprecisas. En la lectura del aparato adviértase que $G^{l}$ y $G^{2}$ representan dos códices diversos y que, en cambio, las correcciones de segunda mano se notan con $a$. $m$. (= altera manu; ahora bien, en el caso de $W$, sus marginalia se notan como $W^{\prime}$ ). Una de las indudables ventajas de ofrecer una edición reposada durante un largo período de tiempo es la maduración en la selectio y la emendatio; en su aparato Estévez Sola remite a publicaciones anteriores, en los que se aborda el texto ahora estampado en la edición.

Cierran el volumen un amplio abanico de índices (pp. 233-263), en los que se recogen los pasajes citados o aludidos de las Sagradas Escrituras, de fuentes o loci 
paralleli literarios, de los pasajes extractados por la tradición indirecta, de nombres de persona y, por último, de nombres de lugar (un elenco particularmente útil para identificar los topónimos latinos).

La factura del volumen es elegante y cuidada. Las erratas, inevitables, son escasas y no afectan a la comprensión del texto. Señalamos de paso las siguientes parua minora: p. 13, ha desparecido el número 14 en voladito de la nota a pie de página; p. 15 crudelia que y p. 81 «otro s», elimínense los espacios en blanco; p. 30 «priuatum» en redonda, no es cursiva (es conjetura al texto, no comentario ecdótico); p. 34 «confunsirse», léase «confundirse»; p. 54 (stemma codicum) el modelo de $W$ no es $B$, sino $V$, $c f$. pp. 43-47 (parece un mero error motivado por el teclado; en el stemma tal vez falte la línea de dependencia que da lugar a $Q$ ); p. 77 n. 86 «cro'nica», acento y vocal están desplazados; p. 100 «porteriormente», léase «posteriormente».

En un tiempo en que el ritmo publicación es a veces vertiginoso, un trabajo maduro y reposado como el presente, en el que se advierte la reflexión y el examen de cada pasaje, merece todo el elogio. De la introducción valoramos en particular su claridad y capacidad de síntesis para abordar de manera condensada, ordenada y elegante los principales puntos oscuros de una obra de tradición escasa, tardía y corrupta, llena de dificultades textuales, plagada de interrogantes históricos, culturales e interpretativos; no nos cabe ninguna duda de que el presente trabajo, en este sentido, será punto de partida para nuevas investigaciones tanto históricas como filológicas. Por lo que se refiere estrictamente al texto latino, la edición de Estévez Sola está llamada a ser el texto de referencia de la Historia Silensis: en una época en la que los historiadores, desgraciadamente, cada vez tienen menos acceso directo a los textos en latín, su mejor complemento sería una traducción española anotada.

\author{
Álvaro Cancela Cilleruelo \\ Universidad Complutense de Madrid \\ alvarocancela@ucm.es
}

